\title{
Mapas conceituais no ensino de matemática: experiência na educação de jovens e adultos
}

\author{
André Ricardo Lucas Vieiral
}

\begin{abstract}
RESUMO
Este estudo analisa o mapa conceitual como estratégia de aprendizagem no ensino de matemática. Concebe o mapa como elemento possibilitador da aprendizagem significativa segundo a teoria de Ausubel (2003). Tem por objetivo compreender como os estudantes de uma turma, na modalidade Ensino Médio da Educação de Jovens e Adultos logram aprendizagem de polígonos a partir do uso que o professor faz do mapa conceitual enquanto uma estratégia didática de ensino. A pesquisa envolveu oito estudantes de uma escola pública estadual do interior baiano. Trata-se de um estudo de base qualitativa, que prima por analisar e descrever fenômenos da subjetividade humana, como o da aprendizagem. 0 método em que o estudo se desenvolveu é o estudo de caso, tendo o questionário e a observação como dispositivos de recolha de dados, a partir da realização de uma oficina que envolveu a construção dos mapas. O estudo evidenciou, dentre outras coisas, que o mapa conceitual possibilita uma apreensão de conteúdos na área de matemática, favorecendo ao estudante a condição de organizar o conteúdo aprendido, de modo a perceber as relações hierárquicas e estruturais de sentidos e conceitos que envolvem um determinado conteúdo em matemática, no caso em tela deste trabalho, polígonos.
\end{abstract}

Palavras-chave: Mapa conceitual. Aprendizagem significativa. Matemática.

\section{Conceptual maps in teaching mathematics: experience in youth and adult}

\section{education}

\begin{abstract}
This study analyzes the conceptual map as a learning strategy in the teaching of mathematics. It considers the map as an enabling element of meaningful learning according to Ausubel's theory (2003). It aims to understand how students in a class, in the High School modality of Youth and Adult Education, manage to learn polygons from the use that the teacher makes of the conceptual map as a didactic teaching strategy. The research involved eight students from a public school in the interior of Bahia. It is a qualitative based study that analyzes and describes phenomena of human subjectivity such as learning. The method in which the study was developed is the case study, using the questionnaire and observation as data collection devices based on the realization of a workshop that involved the construction of maps. The study evidenced, among other things, that the conceptual map allows an

1 Doutorando em Educação - PPGED/UFS. Professor do Instituto Federal de Educação, Ciência e Tecnologia do Sertão Pernambucano, Campus Santa Maria, Pernambuco, Brasil. Orcid iD: https://orcid.org/0000-0002-9279-5802. E-mail: sistlin@uol.com.br
\end{abstract}

Revista Exitus, Santarém/PA, Vol. 10, p. 01-26, e020089, 2020. 
understanding of contents in the area of mathematics, favoring the student the condition of organizing the learned content, in order to perceive the hierarchical and structural relations of meanings and concepts that involve a determined content in mathematics, in the present case of this work, polygons.

Keywords: Conceptual map. Meaningful learning. Mathematics.

\section{Mapas conceptuales en la enseñanza de las matemáticas: experiencia em la educacion juvenil y adulta}

\section{RESUMEN}

Este estudio analiza el mapa conceptual como una estrategia de aprendizaje en la enseñanza de matemáticas. Se concibe el mapa como un elemento habilitador de aprendizaje significativo, de acuerdo con la teoría de Ausubel (2003). El objetivo es entender como los estudiantes de una clase, en la modalidad de Educación de Jóvenes y Adultos de la Escuela Secundaria, logran aprender polígonos através del uso que el maestro hace del mapa conceptual como estrategia didáctica. La investigación se realizó con ocho estudiantes de una escuela pública estatal en el interior de Bahía. Es un estudio cualitativo, que destaca el análisis y la descripción de fenómenos de la subjetividad humana, como el aprendizaje. El método desarrollado es el estudio de caso, utilizando cuestionario y la observación como dispositivos de recolección de datos, basados en la realización de un taller en que hubo actividades de construcción de mapas. El estudio evidenció, entre otras cosas, que el mapa conceptual permite una comprensión de los contenidos matemáticos, favoreciendo la organización del contenido aprendido, como por ejemplo, para entender las relaciones jerárquicas y estructurales de significados y conceptos que incluyen un determinado contenido en matemáticas, en el presente caso de este trabajo, polígonos.

Palabras llave: Mapa conceptual. Aprendizaje significativo. Matemáticas.

\section{Introdução}

Este trabalho emerge de uma pesquisa desenvolvida ao longo do ano de 2018, que tem por objeto o estudo dos mapas conceituais como estratégia potencializadora para o ensino e aprendizagem da matemática no contexto específico da Educação de Jovens e Adultos (EJA). Neste artigo, é feito um recorte para situar a discussão do mapa conceitual na perspectiva da aprendizagem que o estudante logra quando, no chão da escola, se ancora nas diferentes estratégias de ensino que os professores desenvolvem, no caso do estudo em tela, os mapas conceituais em matemática. 
Essa discussão no campo da didática é relevante, pois traz para o cenário das pesquisas em educação o papel do professor e do aluno numa perspectiva relacional de sujeitos que se ensinam e aprendem mutuamente com o cotidiano da escola e de seus modos operativos do fazer pedagógico. Nesta lógica analítica, este trabalho concebe uma imbricação entre os processos de ensino e de aprendizagem que demandam uma relação de contiguidade, em que a aprendizagem mantém estreita relação com os aspectos e natureza do ensino. O contrário é também defendido, na medida em que a aprendizagem ressignifica o ensino, logo, os modos em que estes acontecem no chão da escola.

Pensar a aprendizagem neste contexto significa considerá-la como elemento relevante no espaço escolar, assim sendo, como um elemento que interessa ao campo da didática, que tem como objeto de estudo o ensino, e por consequência a própria aprendizagem, na medida em que, neste trabalho, não se entende o ensino fora da possibilidade de produção de aprendizagem no campo da matemática na Educação de Jovens e Adultos.

O estudo situa-se, portanto, na abordagem de pesquisa de natureza qualitativa, pois foca nas questões da subjetividade e do sentido que $O$ sujeito constrói sobre si e sobre seu percurso formativo. A partir de uma problematização que evidencia a dificuldade que estudantes da EJA têm revelado no que tange à aprendizagem de matemática, este trabalho desenvolveu-se por meio das seguintes questões norteadoras: Como o mapa conceitual possibilita o desenvolvimento de aprendizagem no campo da matemática para estudantes da EJA? Quais sentidos, para aprendizagem matemática, os estudantes atribuem quando elaboram mapas conceituais?

Nesta direção, o objetivo principal da pesquisa é compreender como - mapa conceitual pode se tornar uma estratégia que potencialize o aprendizado relacionado à matemática no contexto da Educação de Jovens e Adultos. Para dar conta desse objetivo, foi elaborado um estudo de caso em uma instituição pública da rede estadual, tendo como colaboradores oito estudantes de uma turma do Ensino Médio da EJA. 


\title{
Percursso metodológico
}

A fim de desenvolver o estudo em questão, a partir da compreensão da realidade social, aqui também entendida como a realidade educacional da Educação de Jovens e Adultos, realizamos uma pesquisa de abordagem qualitativa, defendida por Minayo (2001, p. 15), ao dizer que:

\begin{abstract}
A realidade social é o próprio dinamismo da vida individual e coletiva com toda riqueza de significados dela transbordante. Essa mesma realidade é mais rica que qualquer pensamento e qualquer discurso que possamos elaborar sobre ela.
\end{abstract}

A perspectiva da construção social é a raiz do conhecimento, da cognição e das representações nos campos sociais em sua produção, distribuição e utilização. O processo de construção de conhecimento, marcadamente o do adulto, aluno da EJA, é permeado por suas vivências, cuja lembrança é mobilizada em determinados momentos durante a aprendizagem escolar.

O conhecimento matemático, como as formas de conhecimento, representa as experiências materiais das pessoas que interagem em contextos particulares, em certas culturas e períodos históricos. Considerando essa dimensão social, o sistema educativo - e em particular o sistema escolar - estabelece uma variedade de interações com a comunidade matemática, a fim de garantir que as novas gerações sejam introduzidas aos recursos matemáticos utilizados socialmente e na rede de significados (ou na visão do mundo) dos quais se encontram situados; isto é, organiza um modo de prática matemática (RICO; GOMEZ, 2008).

Desta forma a pesquisa foi desenvolvida por meio dos pressupostos teóricos do estudo de caso. Segundo Yin (2010, p. 39), "o estudo de caso é uma estratégia de pesquisa que investiga um fenômeno contemporâneo em profundidade e em seu contexto de vida real, especialmente quando os limites entre o fenômeno e o contexto não são claramente evidentes". 
Ao definir estudo de caso, Yin (2010) toma por base não apenas as peculiaridades do fenômeno estudado, mas um conjunto de características associadas ao processo de coleta e estratégias de análise de dados.

Para Gil (2009), o estudo de caso possui diversas vantagens, dentre elas, o estímulo às novas descobertas e a flexibilidade no que concerne às ideias iniciais do estudo, posto que, com maior aprofundamento, podem suscitar outros aspectos que não foram previstos inicialmente.

No entanto, para se fazer um bom estudo de caso, três aspectos devem ser considerados: a natureza da experiência, enquanto fenômeno a ser investigado, o conhecimento que se pretende alcançar e a possibilidade de generalização de estudos a partir do método.

Segundo Ponte (2006), na Educação Matemática, os estudos de caso têm sido utilizados para investigar questões de aprendizagem dos alunos bem como do conhecimento e das práticas profissionais de docentes. Desta forma, o autor conclui que os estudos de caso contribuem para um melhor entendimento dos problemas da prática e das instituições educativas, configurando um papel significativo no desenvolvimento do conhecimento em Educação Matemática.

Os dispositivos utilizados para este estudo foram três: a observação, o questionário e as oficinas para a produção dos mapas conceituais. A observação deu-se em todo o processo, desde o momento de chegada à sala de aula para acompanhar o processo, quanto ao modo como cada estudante respondeu ao questionário, que tinha três questões abertas para que narrassem suas experiências com a aprendizagem do mapa conceitual.

As oficinas aconteceram em dez encontros com a duração de duas horas cada encontro. Os alunos tiveram a possibilidade de estudar 0 conteúdo polígonos, por meio de exposição dialogada e diversas atividades desenvolvidas pelo professor, incluindo a construção dos mapas. Neste artigo, tomamos para análise as opiniões dos estudantes no que tange à narração que produziram pelo questionário, pois o objetivo é depreender, aqui, o que os próprios sujeitos trazem no campo do discurso sobre o que 
significou a aprendizagem de polígonos pela estratégia dos mapas conceituais.

O questionário foi composto de três questões discursivas, em que se perguntou: Como você avalia o mapa conceitual para a sua aprendizagem? Em que o mapa conceitual possibilitou/dificultou sua aprendizagem sobre polígonos? Como foi a experiência de usar o mapa conceitual para aprender matemática?

Convém destacar que neste artigo, refletimos sobre as opiniões dos estudantes no que tange à narração que produziram pelo questionário, a partir das questões supracitadas que abordavam comparativamente a possível evolução do aluno ao construir diferentes mapas conceituais. As informações coletadas por meio desse instrumento, nos ajudou a entender, dentre muitos aspectos, quais sentidos se materializaram pela experiência, bem como perceber como os mapas conceituais promoveram aprendizagens de alguns conteúdos.

\section{Mapas conceituais: a aprendizagem significativa em matemática na EJA}

Os mapas conceituais foram introduzidos pelo norte americano Joseph Novak, por volta da década de 70. Mais precisamente em 1972 o professor Novak utilizou pela primeira vez este recurso, que tinha como objetivo representar graficamente a compreensão de conceitos de crianças, a fim de que a evolução do conhecimento pudesse ser acompanhada e entendida.

Novak (1988, p. 32) explicita os fundamentos teóricos do mapa conceitual quando esclarece que se trata de uma projeção prática da teoria da aprendizagem de Ausubel. A partir da perspectiva mais ampla do modelo ou teoria geral da educação, o mapa conceitual está de acordo com um modelo de educação: centrado no aluno e não no professor; que atenda ao desenvolvimento das habilidades e não se conforme somente com a repetição mecânica da informação por parte do aluno; que 
contemple o desenvolvimento de todas as dimensões da pessoa, não somente as intelectuais.

As duas primeiras características provêm da própria definição da aprendizagem significativa. Para Ausubel (1982), aprender significativamente é ampliar e reconfigurar ideias já existentes na estrutura mental e com isso ser capaz de relacionar e acessar novos conteúdos. Quanto maior o número de links feitos, mais consolidado estará o conhecimento.

Os materiais de aprendizagem devem ser bem organizados, as novas ideias e conceitos devem ser "potencialmente significativos" para 0 estudante, ou seja, esse material potencialmente significativo é aquele que é relacional ou incorporável à estrutura cognitiva do estudante, de modo não arbitrário e não literal. Desta forma, ao fixar novos conceitos nas estruturas cognitivas já existentes do aluno fará com que os novos conceitos sejam relembrados, transformando o conhecimento sistematizado, constituindo ligações deste novo conhecimento com os conceitos relevantes que ele já possui.

A terceira relaciona o uso do mapa conceitual como técnica de aprendizagem e tem importantes repercussões no âmbito afetivo do indivíduo, visto que o papel de protagonista dado ao aluno, a atenção e aceitação distribuída e prestada às suas contribuições e o aumento de seu êxito na aprendizagem favorecem o desenvolvimento da autoestima.

Os mapas conceituais têm sido indicados para uma diversidade de atividades. Por exemplo, como: estratégia de estudo, estratégia de apresentação dos itens curriculares e instrumento para a avaliação de aprendizagem escolar.

Desta forma, convém destacar a estratégia como processos executivos mediante os quais, elegem, coordenam e aplicam as habilidades. São, pois, os processos que servem de base para a realização de tarefas intelectuais ou de uma sequência de atividades para chegar a uma aprendizagem (NISBET; SHCKSMIN, 1987, p.12).

Com os mapas conceituais, o indivíduo chega a ter consciência do próprio processo cognitivo. Uma vez que, a codificação é um dos 
componentes das estratégias de aprendizagem, estas podem ser classificadas segundo o critério de níveis de processamento que, por sua vez, coincide com os enfoques de aprendizagem mecânica e significativa de Ausubel.

Nesse sentido, enquanto estratégia para aprendizagem de um novo tópico, a construção de mapas conceituais pode elucidar para o aluno novas formas de produzir reflexões e desenvolver aprendizagens significativas, sendo capaz de organizar o pensamento em uma estrutura relacional, da qual um conceito leva ao outro.

Outro fator comum na definição de mapas cognitivos é a subjetividade do mapa. Costamagna (2001, p. 310) descreve o "mapeamento de conceitos como diagramas do indivíduo e interpretação de ideias". O mapa cognitivo representa graficamente inter-relações de uma variedade de fatores. É uma representação das percepções e crenças de um sujeito sobre o próprio mundo subjetivo, e não necessariamente a realidade objetiva.

Segundo Cañas et al. (2004, p. 1), "os mapas conceituais são uma forma eficaz de representar a compreensão que uma pessoa possui em relação a um domínio de conhecimento".

Para Ausubel (2003, p. 67), "um mapa conceitual proporciona uma visão idiossincrática do criador sobre o fato a que se alude. Quando um sujeito arquiteta um mapa, ele expressa a sua visão madura e intensa sobre um tema", de tal modo que, quando um aluno ou professor constrói o seu mapa cognitivo, ele amplia e experimenta a sua capacidade de apreender as generalidades e distinções do ponto escolhido. Ele pode construir uma hierarquia conceitual, começando com as características gerais, indo para as mais específicas, tornando clara a diferenciação progressiva.

Dadas às várias possibilidades do trabalho pedagógico com mapas conceituais, julgamos oportuno neste estudo analisar como os mapas conceituais podem se constituir como estratégia potencializadora da aprendizagem significativa em matemática na Educação de Jovens e Adultos. Muitas definições podem ser dadas aos mapas conceituais. De 
qualquer forma, para este estudo, utilizaremos a de Novak (2003) a qual afirma, que o mapa conceitual é um recurso capaz de organizar e representar o conhecimento.

Os mapas conceituais expõem as estruturas proposicionais do indivíduo e podem ser empregados, portanto, para verificar as relações equivocadas ou para mostrar quais são os conceitos relevantes que não estão presentes (NOVAK, 2003, p. 129).

Isso faz ampliar a condição de reflexão e tem como consequência melhor qualidade de aprendizagem em relação a complexidade dos conteúdos de matemática; e possibilita que o aluno procure sanar suas dificuldades, em razão de estas, "se não resolvidas ainda nesta etapa, comprometem a aprendizagem ao longo de toda a escolarização" (SANTAROSA; MOREIRA, 2011 , p. 322).

Enquanto recurso de ensino e aprendizagem, os mapas conceituais podem ser elaborados para um curso, uma disciplina, um conteúdo ou um tópico específico. Sob este aspecto, a utilização de mapas pelos docentes para explorar determinado conteúdo matemático pode auxiliar os alunos a perceberem que os conceitos envolvidos não estão desvinculados uns dos outros, ao contrário, em geral se conectam e se complementam.

É importante destacar que a interação entre professor e aluno nesse processo de ensino e aprendizagem, assim como a relação desses sujeitos com o conhecimento pode ser alicerçada com a utilização deste instrumento, pois um novo conceito pode ser apresentado dentro de um diagrama visual organizado, a partir de discussões e conclusões obtidas em sala, em conjunto, durante o processo educativo.

Novak e Godwin (1996) apontam os mapas conceituais como instrumentos simples, funcionais e capazes de explicitar o modo como cada estudante estrutura e correlaciona o conjunto de conceitos aprendidos ao longo de seu processo de aprendizagem. Um mapa conceitual representa graficamente a organização da estrutura cognitiva do seu autor, exibe concepções, domínio do tema, lacunas e equívocos, o que permite ao 
próprio estudante tomar consciência de suas dificuldades e avanços realizados.

A construção de um mapa conceitual é feita utilizando-se figuras geométricas simples e tal construção está vinculada a determinadas regras, sendo elencadas a seguir, porém chamamos a atenção para o fato de esses mapas conceituais não precisarem obrigatoriamente ter esse tipo de hierarquia, pois não há regras fixas para o seu traçado.

Assim, segundo Moreira (2006, p. 60) a construção dos mapas conceituais segue as regras:

1) Identificação dos conceitos chaves, limitando-os a no mínimo 6 e no máximo 10. Ordenar os conceitos, colocando o(s) mais inclusivo(s) na parte superior do mapa e, gradualmente, agregar os demais conceitos na parte inferior deste, até completar o diagrama de acordo com o princípio da diferenciação progressiva.

2) Conectar os conceitos com linhas e rotular essas linhas com uma ou mais palavras-chave que explicitem a relação entre os conceitos e assim sugerir uma proposição que expresse o significado da relação. Evitar palavras-chave que apenas indiquem relações triviais entre conceitos.

3) Buscar relações horizontais e cruzadas.

4) Agregar logo abaixo dos conceitos, caso deseje e possível for, exemplos ao mapa.

5) Utilizar setas para dar um sentido de direção a determinadas relações conceituais, porém não são obrigatórias.

O mapeamento conceitual é um recurso muito flexível e, em razão disso, pode ser usado em diversas situações, para diferentes finalidades. Desse modo, para Moreira (1992, p.13),

[...] se entendermos a estrutura cognitiva de um indivíduo em uma certa área de conhecimento, como o conteúdo e a organização conceitual de suas ideias nessa área, mapas conceituais podem ser usados como instrumentos para representar a estrutura cognitiva do aprendiz. 
E ainda,

[...] os mapas conceituais serão uteis não só como auxiliares na determinação do conhecimento prévio do aluno, mas também para investigar mudanças na estrutura cognitiva durante (e depois) da instrução (MOREIRA, 1992, p.13).

Nesse sentido, ao fazer e refazer um mapa conceitual o aluno frequentemente reflete sobre seus processos cognitivos (MOREIRA, 2010). Dessa forma, justifica-se o trabalho com os mapas conceituais, pois estes podem servir como um mecanismo de tomada de consciência, tanto para professores quanto para os alunos, a fim de acompanhar como está se dando a evolução do aprendizado e demonstrar como os conteúdos matemáticos referentes ao componente estão conectados, numa relação de forte dependência, ancorados na teoria da aprendizagem significativa.

\section{Mapas conceituais para quê? O que dizem os estudantes}

Conforme descrito na seção metodológica, tomamos como elementos de análise três instrumentos, quais sejam: testes de sondagem, os mapas conceituais e o questionário. Neste artigo, refletimos sobre as opiniões dos estudantes no que tange à narração que produziram no questionário, pois o objetivo é depreender, aqui, o que os próprios sujeitos trazem no campo do discurso sobre o que significou a aprendizagem de polígonos pela estratégia dos mapas conceituais, reconhecendo no questionário um instrumento relevante para a validação dos processos de análise que desenvolvemos a partir dos mapas.

Nesse sentido, as respostas dadas nas três distintas questões constituintes do instrumento permitiram-nos analisar tanto as opiniões que os estudantes emitem, como os argumentos utilizados para justificar tais opiniões.

Assim, nesta parte do trabalho, apresentamos algumas das respostas dos questionários e as agrupamos de modo a perceber como elas revelam o que o próprio sujeito diz e entende de seu processo formativo nesta pesquisa. Por questões metodológicas, fizemos a análise considerando o 
conjunto das respostas dadas a cada questão. Isso se justifica pela necessidade de se observar as similaridades e não similaridades que é possível encontrar nas posições que o conjunto de colaboradores adota para responder a uma mesma questão.

Assim sendo, a primeira questão, refere-se a como o estudante avalia o fato de ter construído um mapa conceitual sobre polígonos para a sua aprendizagem nesse conteúdo, demonstra uma predominância de $85 \%$ de respostas que ratificam uma qualificação que sugere aprovação da construção do mapa para o desenvolvimento da aprendizagem. Os qualificadores como, muito boa, interessante, útil e máxima integram nas diferentes respostas a referência ao processo significativo obtido pela construção do mapa. Isso indica que o fato de desenvolver os três mapas no transcurso das oficinas favoreceu condições para que os estudantes se apropriassem de conceitos e definições básicas de polígonos, além da compreensão estrutural do desenvolvimento desse conteúdo, de modo a gerar um favorecimento da percepção cuja a aprendizagem foi uma constante em relação ao conhecimento do conteúdo de polígonos.

A esse respeito, e considerando a natureza do mapa conceitual, Dario $^{2}$ assim responde à questão

Muito boa! Incentiva o saber sobre o assunto e sintetiza-lo de forma objetiva, pois bem aprendemos e organizamos as ideias melhores, além de ser divertido e intuitivo. Precisamos estudar, absorver e organizar no mapa fazendo que as respostas e conceitos fiquem menores e mais objetivos. Uma ótima maneira de guardarmos em nossa mente (Dario, resposta da questão 01, 2018).

A expressão "muito boa" refere-se à aprendizagem desenvolvida por Dario ao considerar a relevância do mapa conceitual no processo. A grande contribuição da estratégia está no fato do estudante poder sintetizar e organizar o que aprendeu de forma objetiva, criando a possibilidade de reunir objetivamente as ideias corretas sobre polígonos, o que para o aluno

2 Os nomes dos colaboradores são fictícios, conforme preconiza o Comitê de Ética em Pesquisa - CEP, ao qual esta pesquisa foi submetida e aprovada. 
significa as melhores ideias. A implicação disso sugere que a organização de informações e conteúdos efetivados no mapa favorece o conhecimento desta, gerando a aprendizagem. Nas palavras do colaborador, o mapa gera condições de produzir conhecimento sobre um assunto de modo sintético e objetivo, permitindo apropriação, pela habilidade de decorar o conteúdo estudado, de modo a guardar isso na mente, ou seja, de modo a finalmente aprender. Nesta abordagem, há uma evidência de aprendizagem memorística, considerando o conhecimento de hoje, contudo esse conhecimento pode integrar a base do modo de aprender significativamente, havendo fixação de maior permanência gerando ancoragens para outras aprendizagens que sejam significativas.

A teoria da aprendizagem significativa de Ausubel reconhece a importância do conhecimento prévio, bem como da relevância do que se aprende por quem aprende. Assim é necessário que aquilo que se aprende o faça sentido, tenha possibilidade de gerar novos conhecimentos e de possibilitar a produção de sentidos para quem aprende. É neste contexto que o mapa conceitual para Dario possibilita uma organização objetiva e sistemática de polígonos, gerando uma aprendizagem muito boa, ou seja, significativa.

O processo de construção da aprendizagem a partir do mapa não é algo linear e que garante sempre que o sujeito aprenda. Há de se considerar a complexidade organizacional de um mapa conceitual e sua natureza epistemológica de organizar o conhecimento a partir das estruturas mentais que cada indivíduo utiliza. Antes de aprender significativamente a organizar o seu conhecimento sobre polígonos, Leandro, outro colaborador, enfatiza em sua resposta que:

A construção do mapa conceitual exigiu de mim conhecimento sobre o tema. Achei interessante. Apesar disso houve uma certa dificuldade de aprender a construir meu primeiro mapa conceitual, contudo a partir do segundo foi se tornando cada vez mais fácil (Leandro, resposta questão 01 , 2018). 
O conhecimento do tema indica que para o estudante conhecer polígono precisa conhecer os conceitos básicos da geometria plana. Esse fato evidencia que a aprendizagem significativa se desenvolve em contextos em que os conhecimentos prévios sejam uma realidade para $o$ estudante. É preciso saber uma coisa para aprender outra e relacionar com tantas outras-e seguir aprendendo ao longo da vida, ou seja, os subsunçores vão adquirindo novos significados, tornando-se diferenciados e, portanto, mais estáveis.

A ideia de estratégia desenvolvida nesta pesquisa denota um sentido de que a própria estratégia, no caso do estudo em tela, os mapas conceituais, evidenciam para o estudante a necessidade de conhecer previamente alguns conteúdos para possibilitar a aprendizagem de outros. Nesse sentido, a organização da aprendizagem num mapa conceitual requer que o estudante esteja mobilizado para conhecer outros conteúdos, que estejam diretamente relacionados com 0 que no momento se desenvolve no mapa.

Para Leandro, a dificuldade inicial incidiu na própria lógica organizativa do mapa conceitual. Assim, primeiro é preciso saber como organizar as ideias no mapa, para só então, poder estruturar o pensamento sobre polígonos, criando as relações deste conteúdo com outros e avançando naquilo que se aprende. Essa lógica ratifica o fato de ter sido necessário iniciar a aprendizagem do mapa conceitual num tema mais geral, aberto e de conhecimento dos colaboradores, como foi o caso, neste estudo, da elaboração do mapa sobre juventude. Ainda, em sua resposta, evidencia que a sequencialidade é sinalizada como uma condição de aprendizagem significativa do assunto, quando este é organizado num mapa. Para ele, esse processo vai ficando melhor compreendido e estruturado a partir do momento que realiza um segundo mapa. Isso indica que ao se apropriar da estratégia e de como realizá-la, consequentemente o que se aprende a partir dela vai ficando, também, mais fácil de ser aprendida e compreendida. 
Nessa ideia, vê-se a possibilidade do mapa conceitual constituir-se de um recurso com múltiplas possibilidades organizacionais, fato que gera distintos modos organizativos da aprendizagem que o sujeito constrói ao longo do seu percurso formativo. Para Douglas, a natureza estrutural do mapa o ajudou a aprender sobre polígonos, a partir de diferentes formas de organizar esse conhecimento no mapa conceitual. Para ele,

A construção do mapa conceitual durante a realização da oficina foi de grande importância, pois possibilitou conhecer diferentes formas de utilização do aplicativo CMAP TOOLS para organização do conteúdo sobre polígonos (Douglas, resposta da questão 01, 2018).

Como utilizamos o mapa num recurso tecnológico do aplicativo CMAP TOOLS 3 o estudante viu nos aspectos da tecnologia os diferentes instrumentos que possibilitam organizar o mapa. Essa observação leva o estudante a considerar o fato de organizar o mapa nessa plataforma de grande valia para a aprendizagem do conteúdo de matemática. Neste sentido é importante abordar o fato de que o ensino de matemática na EJA nem sempre considera possibilidades estratégicas como esta, que além de se constituírem como estratégias de natureza formativas, corroboram com a aprendizagem da matemática e favorecem diferentes perspectivas organizacionais do conhecimento nesta área. Essa condição sugere que o estudante pode utilizar de sua criatividade e poder de organização para demonstrar como aprende o conteúdo. Neste aspecto, o que se aprende torna-se relevante para o sujeito aprendente, como também um dado para o professor de como o sujeito aprende e o que aprende. O mapa além de se constituir como um instrumento de aprendizagem possibilita ao docente avaliá-la de modo mais elucidativo e sequenciado.

No processo de análise, percebemos que os estudantes valorizam o mapa para além de sua natureza epistemológica de promoção da aprendizagem. Ele constitui um novo jeito de aprender matemática,

3 O programa pode ser baixado gratuitamente da internet a partir de um dos links: http://cmaptools.softonic.com.br/ - ativador de download e http://cmap.ihmc.us/download - site oficial do programa. 
oferecendo ao estudante a condição de sentir-se protagonista no processo e considerar com hipervalorização o que aprende. Nesse sentido, o estudante Eduardo considera o mapa como um conhecimento novo, ou melhor, uma forma nova de aprendermos um assunto. Isso muito me ajudará a diferenciar de alguns métodos que já se tornou muito chato (Eduardo, Resposta da questão 01, 2018). Assim, o mapa conceitual surge na contramão de métodos e técnicas predominantes para o ensino de matemática na EJA, como é o caso de aulas expositivas que, nem sempre, levam em consideração o conhecimento prévio do aluno.

Na segunda questão do questionário, perguntamos aos estudantes se a construção de mapas conceituais influenciou de alguma forma o seu desempenho no teste aplicado sobre o conteúdo trabalhado. Além disso, pedimos para os estudantes justificarem suas respostas. No conjunto dos oito estudantes, sete revelam o sim como resposta, evidenciando a diferença no desempenho do teste.

Pela natureza das respostas é possível inferir que a aprendizagem foi determinante no processo, gerando no teste o maior número de acertos. Isso implica no reconhecimento de que o desempenho foi outro, para o estudante, e de certo modo satisfatório. A organicidade e a objetividade demarcam situações de aprendizagens que podem ser evidenciadas no questionário, sobretudo quando se analisa respostas como a de Dario, que responde a essa questão abordando o modo como o mapa o ajudou na aprendizagem do conteúdo. Para ele,

\footnotetext{
Sim, logo após começar a trabalhar com os mapas meu conhecimento sobre o assunto ficou bem melhor e mais objetivo, além de relembrar fórmulas e aprender novas, além de novos conhecimentos e conseguir organizar melhor minhas ideias sobre o assunto (Dario, resposta da questão 02, 2018).
}

Há uma subjetividade na resposta de Dario que não é objeto de investigação neste estudo, mas que de alguma forma indica o modo de compreensão que tem sobre os mapas conceituais e sua relação com o processo de ensino e aprendizagem na matemática. Afirmar que o seu 
conhecimento ficou bem melhor, e mais objetivo, indica uma possibilidade de reconhecimento na qual o estudante considera haver uma aprendizagem que, se comparada com as que lograva antes da realização do mapa é, no mínimo, diferenciada. No entanto, no contexto da própria afirmação, a objetividade e a diferença em sua aprendizagem indicam que ele percebe um elemento significativo, o qual o possibilita apropriar-se daquilo que aprende.

"Os mapas favorecem uma releitura dos conhecimentos prévios, por meio dos quais ele relembra fórmulas e aprende outras, garantindo uma progressão de aprendizagem que se constrói numa rede de conhecimentos e relações que vão ganhando sentido na tessitura do próprio mapa conceitual" (VIEIRA, 2018, p. 131). Trata-se, portanto, de uma aprendizagem que se efetiva de modo a gerar articulações entre conceitos, caracterizações, fórmulas e outras definições dos conteúdos necessários para se entender polígonos. O processo de sistematização e de síntese figura, também, como modo operativo de uma aprendizagem significativa na matemática no contexto de um estudante da EJA.

Com resposta similar à de Dario, o estudante Leandro considera que os mapas conceituais o oportunizaram bom desempenho no teste, uma vez que precisou relembrar de outros conteúdos, associar e relacionar ideias para desenvolver a aprendizagem sobre polígonos. Em sua resposta a essa questão, Leandro nos diz que:

Com a construção do mapa conceitual eu pude conhecer e relembrar conteúdos antigos, por isso acredito que a construção dos mapas conceituais tenha contribuído bastante para o meu desempenho no teste (Leandro, resposta da questão 02, 2018).

Conforme Macedo (1994) o sujeito desenvolve aprendizagem de acordo com o seu arsenal cognitivo, mas também de acordo com o seu cotidiano, logo com o que vive, convive, desenvolve, etc. No caso de Leandro, vemos que a inserção do mapa conceitual gerou condições cognitivas de aprendizagem, as quais garantiram ao estudante um bom 
desempenho no teste. A realidade dele, como dos demais sujeitos desta pesquisa, é a realidade de estudantes da EJA, que estão inseridos num contexto de particularidade gerando maior dificuldade para estes. São estudantes de curso noturno, que geralmente trabalham durante o dia e estão, numa distorção idade/série/ano que dificulta um pouco o processo de aprendizagem.

É neste contexto, de pensar a realidade do aluno, e as suas dimensões cognitivas na realidade em que se encontra na escola que retomamos a ideia sobre, como bem fundamenta Freire (2015), ensinar exige apreensão da realidade de como o sujeito aprende. Assim sendo, os resultados evidenciados nas análises que temos produzido a partir dos questionários mostram que os estudantes nem sempre representam suas aprendizagens mecanicamente, sem a condição de demonstrarem como os sentidos se configuravam de forma positiva, a fim de garantir que a aprendizagem ocupe uma dimensão significativa.

Os mapas enquanto estratégias de aprendizagem vão possibilitando outros modos de conhecer e de gerar uma aprendizagem não mecânica, não repetitiva e que promova no sujeito algum sentido para aquilo que aprende, logo, uma aprendizagem significativa, como assevera David Ausubel em seus estudos sobre a temática.

É desse lugar de compreensão de avançar e de aprender significativamente que o estudante Douglas considerou 0 sim em sua resposta a essa questão, argumentando que durante a construção dos mapas conceituais foi possivel perceber a necessidade do aprofundamento do conteúdo para que fosse possivel estabelecer relações entre os tópicos (Douglas, resposta da questão dois, 2018). Assim, o estudante revela que a aprendizagem ocorre numa condição de aprofundamento do conteúdo, sobretudo pelos estabelecimentos de relações conceituais as quais se processam como elemento básico na construção de mapas conceituais. Cabe, portanto, a defesa de que a condição de aprofundamento, bem como a de criação de relações entre distintos assuntos, faz-se de modo 
estruturado, dentre outras estratégias, com o uso de mapas conceituais nas aulas de matemática.

Foi curioso observar a resposta negativa dada a essa questão por um dos colaboradores. Para ele o mapa não impactou no seu desempenho no teste,

[...] porque construí o mapa com conteúdos básicos de um campo de conhecimento próprio, isto é, não me veio em mente pesquisar além sobre o conteúdo. Acredito que aí foi meu ponto fraco (luri, resposta da questão 02, 2018).

Ao dizer que o mapa não influenciou no seu desempenho no teste, o colaborador argumenta o fato de ter respondido apenas com 0 conhecimento de que dispunha, logo com os conhecimentos prévios, que apesar de necessários à construção do mapa, não figuraram no seu.

A construção de qualquer estratégia, sobretudo seu uso tendo em vista o desenvolvimento de alguma aprendizagem, requer que o sujeito desenvolva a atitude de implicar-se no processo e de aproveitar a tessitura da estratégia para apropriar-se de diferentes modos de aprender um conteúdo. Entre as condições, está a de constante estudo sobre o que é necessário saber para avançar na construção de outros conhecimentos. Esse parece não ter sido o caso do estudante, que atribui a sua atitude, de não ter estudado e feito o mapa com empenho, o fato de não ter logrado um impacto positivo no teste.

No que se refere à terceira e última questão aplicada, fizemos diretamente e de modo bastante objetivo a seguinte indagação: Como o processo de construção de um mapa conceitual o ajudou na aprendizagem de polígonos? Esclarecemos que consideramos essa questão bastante relevante para que pudéssemos compreender as diferentes perspectivas que os alunos utilizaram para aprender o conteúdo. Em outras palavras, com essa questão pretendíamos encontrar elementos que nos permitissem aferir o papel dos mapas conceituais no que tange ao desenvolvimento da aprendizagem de polígonos pelos estudantes participantes deste estudo. 
Nesse contexto, encontramos respostas que mostraram a variação do papel de contribuição dos mapas.

Há de se considerar que parece haver certo consenso dos estudantes para o papel organizador do mapa conceitual. Assim, a aprendizagem se efetiva numa organização que exige uma sequenciação lógica, por vezes linear, de estruturas conceituais e de caracterizações de polígonos. Para Luciano,

De alguma forma organizou as ideias e me fez relembrar o conteúdo de polígonos. O professor teve um papel fundamental para a minha aprendizagem pelo fato de que particularmente eu não sabia o que era um mapa conceitual (Luciano, resposta da questão 03, 2018).

A organização das ideias indica que a aprendizagem acontece em fases e etapas e que tem conexão relacional com os conhecimentos prévios. Ademais, há um reconhecimento de que aprender e relembrar o conteúdo em torno dos conhecimentos que tinha de polígonos só se efetivou pela aprendizagem inicial do que é um mapa e de como o mapa favorece a aprendizagem. Já Douglas considera relevante o processo de construção dos mapas, pois junto a este desenvolvimento se adjunge a compreensão de que os conteúdos não são soltos e que entre eles há uma relação conectiva, que de alguma maneira, organiza e facilita o processo de aprendizagem. Assim, em sua resposta o estudante considera que:

Foi durante a construção dos mapas conceituais que foi preciso conhecer o conteúdo de forma que pudesse estabelecer ligações entre os tópicos. Portanto, a construção dos mapas conceituais contribuiu de forma significativa para a aprendizagem do conteúdo sobre os polígonos (Douglas, resposta da questão 03, 2018).

O padrão de sequência de ligações é o elemento chave que toma Douglas para demarcar a condição dos mapas possibilitarem desenvolver uma aprendizagem significativa referente ao conteúdo de polígonos. Tratase, contudo, de uma afirmação cujo o próprio participante diz quando reflete sobre o lugar dessa estratégia no seu percurso formativo. Logo não é 
o mapa em si que gera a aprendizagem, mas a complexidade que está em torno do processo de construção deste, que envolve condições de reflexão e desenvolvimento de saberes relativos ao conteúdo estudado. Nesta lógica, e pelo que sinaliza o participante, o mapa se coloca no cenário de uma estratégia que se potencializa tanto para $o$ ensino como para a aprendizagem.

Getúlio em perspectivas semelhantes considera o mapa como um instrumento possibilitador de uma leitura transversal e organizacional do conteúdo, permitindo-Ihe ver o todo aprendido e revisar o conteúdo pela sistematização e síntese. Em sua resposta o estudante nos diz que:

Através dos conceitos de ligação, o sujeito relaciona os elementos e as características do conteúdo. No meu ponto de vista é o que mais contribuiu para a minha aprendizagem. Depois de feito, o mapa conceitual é um bom instrumento para revisar conteúdos (Getúlio, resposta da questão 03, 2018).

Em pensamento e argumento de modo semelhante, Elis considera em sua resposta que:

Polígonos é um assunto muito complexo e extenso. A construção de mapas conceituais foi importante para que eu saiba sintetizar os tantos tópicos do tema, sem dúvida enriqueceu meu conhecimento sobre o assunto e somou para meu aprendizado (Elis, resposta da questão 03, 2018).

Tanto um estudante como o outro consideram que o mapa conceitual se constitui como uma estratégia que possibilita organizar de modo esquemático o conteúdo, podendo criar relações de aprendizagem configurando-se numa complexidade que se resolve pelo próprio mapa. Consideram que o conteúdo de polígono é complexo, num reconhecimento sobre a referida estratégia possibilitar o enriquecimento da aprendizagem, logo promoção de uma aprendizagem para a qual se vê um sentido.

Ao analisar as respostas das três questões, percebemos que, de algum modo, os mapas conceituais se inserirem numa dinâmica de aprendizagem ainda não conhecida por estes sujeitos, mas que despertou interesses em 
querer aprender e nisso ver que há possibilidades de tornar a aprendizagem em matemática algo possível e ainda contribuir com o desenvolvimento cognitivo. Ensinar, como assevera Freire (2015) vai além de transmitir conhecimento ou conteúdo. O ensino pressupõe a utilização de estratégias que transcendam a essa lógica e levem o sujeito a aprender de modo significativo e útil aquilo que aprende.

Desta forma, o processo de ensino e aprendizagem é uma construção permanente de conhecimentos, adquiridos com a passar da vida. É nessa construção, e no trabalho com a Matemática, que os alunos da EJA buscam desse aprendizado e esperam que os professores sejam capazes de inovar, e com o uso de estratégias adequadas potencializar uma aprendizagem que seja efetivamente significativa.

É neste campo que percebemos uma linearidade nas respostas das três questões, evidenciando que para o sujeito aprendente $\circ$ mapa conceitual pode ser uma estratégia motivadora e que impacta nos modos como cada um aprende. Isso tem uma dimensão significativa e avaliativa do trabalho com matemática, que tem sido alvo de críticas por se desenvolver numa tradição de aulas expositivas em desconsiderar, em muitos casos, o contexto de vida dos estudantes, sobretudo o contexto do conhecimento prévio, necessário para o desenvolvimento da aquisição de novos conteúdos. Assim, os mapas impactam nos resultados de aprendizagem, bem como nos aspectos de como cada estudante percebe e atribui sentido para aquilo que estuda, no caso da pesquisa em tela, para polígonos.

\section{Considerações finais}

O estudo possibilitou a compreensão de que a aprendizagem na área de matemática se constitui um desafio para os estudantes da EJA, tanto pela complexidade dos próprios conteúdos relativos ao componente, como pela dificuldade natural de um sujeito que está numa temporalidade formativa não linear. Em outras palavras, os estudantes da EJA encontram-se 
numa distorção de idade/etapa de ensino que, por si só, já se apresenta como elemento problematizador da aprendizagem desses sujeitos.

Na perspectiva de compreender como o mapa conceitual pode se tornar uma estratégia que potencialize a aprendizagem na matemática no contexto da Educação de Jovens e Adultos, os mapas conceituais caracterizaram-se como uma excelente estratégia de aprendizagem, uma vez que, no curso de sua organização e reorganização, revelaram-se conflitos cognitivos e espaços para a compreensão sobre erros, problemas, divergências e dificuldades - que, quando analisados, confrontados, discutidos, explorados, apresentaram-se como espaços de avanços e superações. É, portanto, neste contexto, que se pode observar como os mapas conceituais se constituíram enquanto uma estratégia de aprendizagem que favorece a aprendizagem significativa para os sujeitos. No caso específico deste recorte, o que permitiu tal conclusão foram as respostas que os estudantes deram ao questionário, por meio do qual expressaram os sentidos que cada um imprimiu para evidenciar como a aprendizagem se instaurou como uma possibilidade de entendimento e significação de polígonos por meio dos mapas conceituais.

Na dinâmica do estudo de caso, o questionário caracterizou-se como um instrumento relevante para a validação dos processos de análise, logo de apreensão de como os sujeitos percebem a aprendizagem a partir dos mapas. O questionário trouxe a posição de cada sujeito em torno do que aprendeu, mostrando como cada um entende e reflete sobre a aprendizagem de polígonos em mapas conceituais.

Nesse sentido, as respostas dadas permitiram analisar tanto as opiniões emitidas pelos estudantes, como os argumentos utilizados para justificar tais opiniões. Nesse percurso, foi possível observar como cada um construiu para si a reflexão sobre a aprendizagem que desenvolveu, bem como perceber que com o conjunto das respostas possibilitou-se concluir que os mapas constituíram-se como uma estratégia de aprendizagem significativa na matemática. 
Pelas questões metodológicas do recorte aqui feito, a análise seguiu-se considerando o conjunto das respostas dadas a cada questão, sendo possível observar como cada colaborador expressa o lugar da aprendizagem significativa a partir dos mapas. Considerando os qualificadores que aparecem no conjunto das respostas dos estudantes, é possível perceber a existência de uma valorização em relação aos qualificadores de natureza positiva para demarcar a aprendizagem de polígonos a partir dos mapas. Nesse contexto, verifica-se a predominância de $85 \%$ de respostas que ratificam uma qualificação que sugere a aprovação da construção do mapa para o desenvolvimento da aprendizagem. Os qualificadores como, muito boa, interessante, útil e máxima integraram nas diferentes respostas a referência ao processo significativo que se deu pela construção do mapa. Isso indica que os estudantes apropriaram-se de conceitos e definições básicas de polígonos, além da compreensão estrutural e desenvolvimento desse conteúdo, de modo a gerar um favorecimento da percepção de que a aprendizagem foi uma constante no que tange ao conhecimento de polígonos, marcando-a como uma aprendizagem significativa.

De modo geral, o estudo possibilita a reflexão de outras questões e modos de conceber o ensino e aprendizagem de Matemática a partir dos mapas conceituais. Há uma possibilidade variada de análise que pode ainda ser feita sobre os dados coletados, dando-me, não só a sensação, mas a certeza de que muita coisa ainda há de ser estudada no campo da EJA, no que tange ao uso de mapas conceituais como estratégia de aprendizagem em Matemática.

Assim, é possível perceber a existência de vários desdobramentos da pesquisa e isso revela uma possibilidade de estudos futuros nesse campo, que possam ampliar a discussão feita aqui sobre como uma estratégia de aprendizagem que pode tornar-se significativa, ou seja, uma viabilidade didático metodológica de professores que atuam na EJA potencializarem seus ensinos, logo as aprendizagens dos estudantes. 


\section{Referências}

AUSUBEL, D. P. Aquisição e retenção de conhecimento: uma perspectiva cognitiva. Tradução: Lígia Teopisto. Lisboa: Plátano Edições Técnicas, 2003.

CAÑAS, A. J. et al. Cmap Tools: A Knowledge Modeling and Sharing Environment. In: CAÑAS, A. J.; NOVAK, J. D.; GONZÁLEZ, F. M. (Orgs.). Concept Maps: Theory, Methodology, Technology, Proceedings of the First International Conference on Concept Mapping. Universidad Pública de Navarra: Pamplona, Spain, p. 125-133, 2004. Disponível em: <http://cmap.inmc.us/Publications/>. Acesso em: dez. 2018.

COSTAMAGNA, A. M. Mapas conceptuales como expresión de procesos de interrelación para evaluar la evolución del conocimiento de alunos universitarios. Enseñanza de las Ciencias. Barcelona, 2001.

FREIRE, P. Pedagogia da autonomia: saberes necessários à prática educativa. $52^{a}$ ed. Rio de Janeiro: Ed. Paz e Terra, 2015.

GIL, A. C. Métodos e Técnicas da Pesquisa Social. $6^{a}$ ed. São Paulo: Atlas, 2009.

MACEDO, L. Ensaios Construtivistas. São Paulo: Casa do Psicólogo Livraria e Editora Ltda., 1994.

MINAYO, M. C. S. Pesquisa Social. Teoria, método e criatividade. 18 ed. Petrópolis: Vozes, 2001.

MOREIRA, M. A. Mapas conceituais no ensino de física. Porto Alegre: Instituto de Física da UFRGS, 1992.

MOREIRA, M. A. A teoria da aprendizagem significativa e sua implementação em sala de aula. Brasilia: Editora da UNB, 2006.

MOREIRA, M. A. Aprendizaje Significativo Crítico. Boletín de Estúdios e Investigación, $2^{a}$ ed, $n^{\circ}$ 6, p. 83-101, 2010.

NISBET, J.; SHCKSMIN, J. Estrategias de aprendizaje. Madrid: Santillana, 1987.

NOVAK, J. D.; GOWIN, D. B. Aprender a aprender. Lisboa: Plátano, 1996.

NOVAK, J. D. Aprendiendo a aprender. Barcelona: Martínez Roca, 1988.

NOVAK, J. D. The Theory Underlying Concept Maps and How To Construct Them. Cornell University, 2003. 
PONTE, J. P. Estudos de caso em educação matemática. Bolema, 25, p.105$132,2006$.

RICO, L.; GOMEZ, J. L. L. Competencias Matematicas desde uma perspectiva curricular. Barcelona - Espanha: Alianza Editoral Sa, 2008.

SANTAROSA, M. C. P.; MOREIRA, M. A. O Cálculo nas aulas de Física da UFRGS: um estudo exploratório. Investigaçōes em Ensino de Ciências, v. 16, p. 317-351, 2011.

VIEIRA, A. R. L. Mapas conceituais como estratégia de aprendizagem significativa em Matemática na Educação de Jovens e Adultos: Um estudo com polígonos. 168f. 2018. Dissertação (Mestrado). Departamento de Educação, Campus I, Universidade do Estado da Bahia, Salvador, 2018.

YIN, R. K. Estudo de caso: planejamento e métodos. 4. ed. Porto Alegre: Bookman, 2010.

Recebido em: 15 de março de 2020 Aprovado em: 22 de junhode 2020 Publicado em: 04 de setembro de 2020 